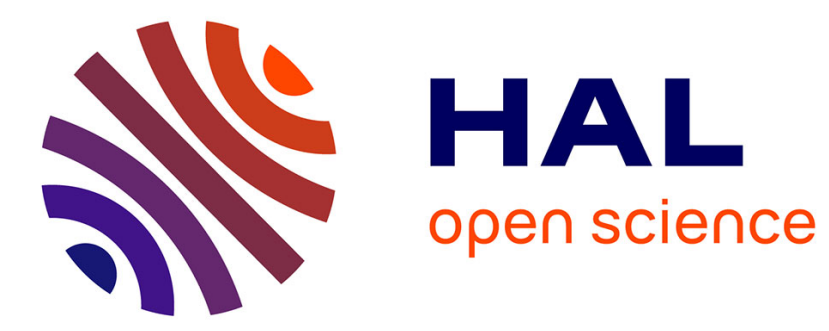

\title{
DENSITY OF ELECTRONIC STATES IN fcc T1-Pb-Bi ALLOYS
}

\author{
Felienne Hermans, J.C. Ho, J. Boyer, N. Phillips
}

\section{To cite this version:}

Felienne Hermans, J.C. Ho, J. Boyer, N. Phillips. DENSITY OF ELECTRONIC STATES IN fcc T1-Pb-Bi ALLOYS. Journal de Physique Colloques, 1978, 39 (C6), pp.C6-477-C6-478. 10.1051/jphyscol:19786213 . jpa-00217633

\section{HAL Id: jpa-00217633 https://hal.science/jpa-00217633}

Submitted on 1 Jan 1978

HAL is a multi-disciplinary open access archive for the deposit and dissemination of scientific research documents, whether they are published or not. The documents may come from teaching and research institutions in France or abroad, or from public or private research centers.
L'archive ouverte pluridisciplinaire HAL, est destinée au dépôt et à la diffusion de documents scientifiques de niveau recherche, publiés ou non, émanant des établissements d'enseignement et de recherche français ou étrangers, des laboratoires publics ou privés. 
DENSITY OF ELECTRONIC STATES IN $\mathrm{f} c \mathrm{c}$ Tl-Pb-Bi ALLOYS."

E. Hermans, J.C.Ho, J.Boyer and N.E. Phillips

Materials and Molecular Research Division, Lawrence Berkeley Laboratory, University of Catiformia/Berkeley, Berkeley, Catiformia 94720 .

Résumé.- Nous avons mesurê $\mathrm{la}$ chaleur spêcifiqque d'alliages cubiques du système $\mathrm{T} 1-\mathrm{Pb}-\mathrm{Bi}$, et nous avons utilisé les valeurs de $\lambda$ de Dynes et Rowell pour calculer $N(0)$. Le comportement de $\lambda$ ne montre pas de corrélation simple avec $\mathrm{N}(0)$ ou $\left\langle\omega^{2}\right\rangle$.

Abstract.- We have measured the heat capacity of fcc $\mathrm{Tl}-\mathrm{Pb}-\mathrm{Bi}$ alloys, and have used values of $\lambda$ published by Dynes and Rowell to obtain $\mathrm{N}(0)$ and the other component factors in $\lambda$. The behavior of $\lambda$ shows no simple correlation with other properties.

The density of electronic states at the Fermi surface, $N(0)$, is of fundamental importance in determining many of the properties of metals including $T_{c}$, the critical temperature for superconductivity. It can be derived from the electronic heat capacity, $\gamma \mathrm{T}$, and the relation

$\gamma=(2 / 3) \pi^{2} k^{2}(1+\lambda) \mathrm{N}(0)$,

if $\lambda$, the electron-phonon interaction parameter, is known. The latter quantity has generally been available only for pure metas, and the recent tunnelling measurements /1/ on $\mathrm{fcc}$ alloys of the $\mathrm{T} 1-\mathrm{Pb}-\mathrm{Bi}$ system provided the incentive for the heat capacity measurements reported here. This series of alloys is of particular interest because $\lambda$ and $T_{c}$ are strong functions of the electron/atom ratio $z$. Furthermore, the combination of tunnelling and heat capacity data permit a complete analysis of $\lambda$ in terms of electronic and lattice properties through the relation/2/ $\left.\lambda=\mathrm{N}(0)<\mathcal{L}^{2}\right\rangle / \mathrm{M}\left\langle\omega^{2}\right\rangle$

where $d$ is a matrix element for the scattering of an electron, $M$ is the atomic mass, and $\left\langle\omega^{2}\right\rangle$ is a mean square phonon frequency. McMillan /2/observed that for five transition metals $\mathrm{N}(0)<\mathbb{Q}^{2}>$ was approximately constant and the values of $\lambda$ and $T_{c}$ were determined by the phonon spectrum. He suggested that this might be a more general relation, and since then the assumption $\lambda \propto 1 /\left\langle\omega^{2}\right\rangle$, together with Eq. (2) and McMillan's expression /2/ for $T_{c}(\lambda)$, has been wide$1 y$ used to interpret variations of $T_{c}$. This is in marked contrast to earlier practice, in which it waw more of ten assumed that variations in $T_{c}$ were determined primarily by electronic properties, and in particular by $\mathrm{N}(0)$. As will be shown below,

This work was supported by the Division of Materials Sciences, Office of Basic Energy Sciences, U.S. Department of Energy. neither of these simple correlations is consistent with the data now available for the $\mathrm{T} 1-\mathrm{Pb}-\mathrm{Bi}$ system.

Norma1-state heat capacity data and zero-field data near $T_{c}$ have been obtained for binary alloys with conduction electron/atom ratio $z$ ranging from 3.4 to 4.2 , and for three "pseudo leads," ternary a1loys of the form $\mathrm{Pb}{ }_{1-2 x} \mathrm{x}^{\mathrm{T} 1} \mathrm{x}^{\mathrm{Bi}} \mathrm{x}_{\text {with } \mathrm{x}}=0.05,0.10$, 0.15 . Values of $\gamma, T_{c}$, and the Debye characteristic temperature, $\theta$, were derived. Values of $\lambda$ were derived from the published/1/data, and used to calculate $N(0)$ from $\gamma$.

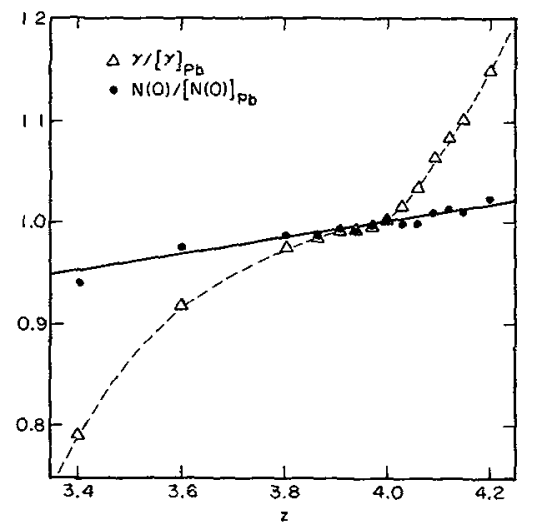

Fig. I : Coefficient of electronic heat capacity and density of electronic states for the binary alloys, normalised to their values for $\mathrm{Pb}$.

The results for both $\gamma$ and $N(0)$ for the binary alloys are shown in figure 1. A striking feature of figure 1 is that although the slopes of $r \mathrm{vs} . z$ are different for the $\mathrm{Tl}-\mathrm{Pb}$ and $\mathrm{Pb}-\mathrm{Bi}$ alloys, the values of $N(0)$ fall on a common straight line to within $0.5 \%$, the apparent precision of the data Furthermore, although the values of $\gamma$ for $\mathrm{Pb}_{0.9}$ 
$\mathrm{T}_{0.05^{\mathrm{Bi}}} 0.05^{\text {and } \mathrm{Pb}} 0.8 \mathrm{Tl}_{0.1} \mathrm{Bi}_{0.1}$ are 3.5 and $6.5 \%$ greater than for $\mathrm{Pb}$, the values of $\mathrm{N}(\mathrm{O})$ are the same for all three to within $0.5 \%$ In these respects the results are consistent with the rigid-band model, but in light of what is now known about the electronic structure of alloys, that must be regarded as either a concidence or indicative of some hitherto unrecognized correlation. The slope of $N(0)$ vs.z, however, is not in agreement with that derived from band-structure calculations /3,4/ for $\mathrm{Pb}$. (Earlier heat capacity data /5/ on binary alloys with 3.90 $<z<4.09$ were interpreted as being in agreement with the calculated $\mathrm{Pb}$ band structure and the rigidband model. However, the $\gamma$ values were of lower precision and the $\lambda$ values used in the analysis were not in good agreement with the more recent results.

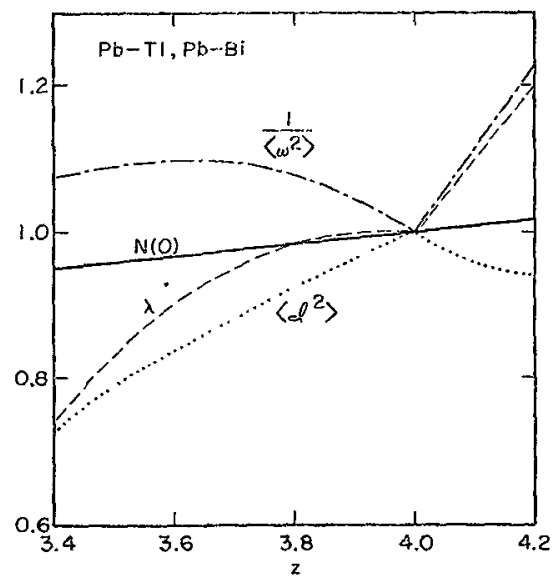

Fig.2: and its component factors for the binary alloys, normalised to their values for $\mathrm{Pb}$.

Smooth curves representing the $z$ dependence of $\lambda$ and its component factors for the binary alloys are shown in figure 2. The $x$ dependence of the same quantities for the ternary alloys is shown in figure 3.The curves are based on data reported by Dynes and Rowell /1/ for $\left\langle\omega^{2}\right\rangle$ and on the values of $N(0)$ and $\lambda$ derived above. $\left\langle d^{2}\right\rangle$ was calculated from Eq. (2). Throughout the range of $z$ studied $N(0)$ is essentially constant and the trends with $z$ of $\left\langle\omega^{2}\right\rangle$ and $\left\langle Q^{2}\right\rangle$ are in opposite directions. The net effects for the two alloy systems are quite different, however : for $\mathrm{Pb}-\mathrm{Bi}$ alloys and increasing $\mathrm{z}$, the strong increase in $\left\langle\omega^{2}\right\rangle^{-1}$ dominates the decrease in $\left\langle\lambda^{2}\right\rangle$ and produces the observed increase in $\lambda$; for $\mathrm{T} 1-\mathrm{Pb}$ alloys and $z>3.8$ the two effects more nearly can- cel and $\lambda$ is essentially constant : for $z<3.8$ the trends in $\left\langle d^{2}\right\rangle$ and $N(0)$ dominate the behavior of $\lambda$. For $\mathrm{Pb}-\mathrm{Bi}$ alloys, McMillan's correlation/2/ is approximately correct and the trend in $\lambda$ is determined largely by changes in the phonon spectrum for the $\mathrm{T} 1-\mathrm{Pb}$ alloys on the other hand it is large$1 y$ the electronic properties that determine $\lambda$.

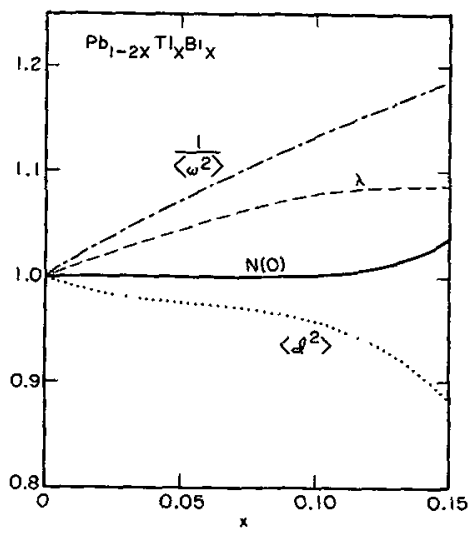

Fig.3 : and ist component factors for the "pseudo leads", normalised to their valuers for $\mathrm{Pb}$.

The dip in the $\lambda$ vs. $z$ curve at $z=4$ (figure 2) and the positive slope of the $\lambda$ vs. $x$ curve (figure 3) reflect the softening of the lattice associated with alloying. The behavior of $\left\langle\omega^{2}\right\rangle$ for the binary alloys near $z=4$ and for the ternary alloys corresponds closely to that of the calorimetric values of $\vartheta$ for this system, and is similar to that observed in many other alloy systems.

\section{References}

/1/ Dynes,R.C. and Rowe11;J.M., Phys.Rev.B 11 (1975) 1884

/2/ McMillan,w.L., Phys.Rev. 167 (1968) 331

/3/ Anderson,J.R. and Gold,A.V., Phys.Rev. 139 (1965) A 1459.

/4/ McFeely,F.R., Ley,L., Kowalczyk, S.P., and Shirley,D.A., Solid State Commun. 17 (1975) 1415 15/ Clune,L.C. and Green,B.A., Phys.Rev. B 1 (1970) 1459 